\title{
Study on the Advance Payment Rate of Advance-Payment Collection Business Based on Logistics Financial
}

\author{
Weiguo Cao, Yong Zhang \\ Institute of Management Science and Information Engineering, Hangzhou Dianzi University, Hangzhou,China \\ Email: caowg@hdu.edu.cn, zhang.yong666@163.com
}

Received 2012

\begin{abstract}
This paper takes the advance-payment collection business based on the logistics financial as the research object, on the assumption that the logistics enterprises pay the price with their own money,and the shipper repurchases the goods unconditionally when the delivery breaks rule. From the point of logistics enterprises to quantitative analyze its key indicators of risk management and control - advance payment rate, expectations for providing a scientific basis of decision making for the business risk of logistics enterprises in China, in order to solve the outstanding contradictions between a lot of money tied up in inventory and difficulties in financing of SMEs,and provide a decision support from the side of management techniques.
\end{abstract}

Keywords: Logistics Financial; Advance-layment Collection Business; Advance Payment Rate

\section{Introduction}

There is a saying in the G20 summit held this year,saying that if you can find a key to increase employment, go out of the poverty and financial crisis of the world , then this golden key must be the healthy development of SMEs, so we can see the SMEs' great importance to global economic development. However, currently, the difficulties in financing of SMEs has become a big bottleneck that restricting economic development significantly, although the banks and other financial institutions have adequate capital, face the shortage of funds for SMEs, only have the "prudent loan refused credit crunch" attitude. In recent years, with the rapid development of logistics industry,in order to find new profit growth point, logistics enterprises innovative value-added services and develop many new business model of funds shortage for SMEs continuously, based on the theory of logistics financial. At present, some large logistics companies have started to provide logistics financial services, for example, Since 1999 the China Logistics jointly with the banks developed the first inventory pledge financing business, to the present, it has been cooperated with the Industrial and Commercial Bank, Construction Bank, Agricultural Bank, Merchants Bank and more than a dozen financial institutions, To carry out the inventory pledge financing business, release credit to SMEs and solve the financing problem.

Because of its expertise, logistics companies have a great advantage in providing the logistics financial services. Drawing on the successful experience of UPS, logistics companies develop the advance-payment collection business can solve the financing problems of SMEs effectively. Currently there are some third-party logistics companies started trying to do payment collection business, such as postal EMS, home delivery, JiaJie fast delivery, etc, but no one has combined the advance and payment collection services.This paper is based on the deficiency,trying to study the decision-making problems of logistics companies when they carry out the advance-payment collection business.

\section{The Development Status of Advance-Payment Collection Business}

Advance-payment collection business as a business model of logistics financial services provided by logistics companies, there are few literature devoted to the study both domestic and foreign. But in the practical application, it had indeed been well developed. The most successful is the UPS,in the advancepayment collection business, when UPS carry the shipment for shipper, it paid half of the advance payment for the delivery, then the delivery paid all the money to logistics companies when it receives shipment.Before UPS give the other half money to the shipper, it proceeds a time difference of capital movement, this part of the funds is in a deposition before the delivery period. During the precipitation period, UPS received a sum of money without interest. Then UPS utilizes the funds for loans through its own financial institutions, and the borrowers are still limited to UPS' customers or delivery business. This business model not only accelerate the customer's working capital turnover, improve the client's financial situation,but also save the inventory holding costs and cost of operating logistics services network for customers.

Domestic research mainly focused on the payment collection business. Feng Xia analyzes the development status and bottleneck of payment collection business carried out by TPL in China, give some related suggestion for TPL to carry out payment collection services. Wong Ka Kui and Chen Fulai take the healthy development of postal-delivery payment collection business into consideration, analyze its problems and the reasons for these problems,and explore solutions to these problems. Wang Junfeng also stand on the position of the postal, from the "dark hole" which hidden behind the postal business operation mechanism , proposed the "two major difficulties" and causes that restrict the development of the business, and discussed how to break the "two difficulties". What we can see from the research 
has been studied is that they are mainly discuss the problems and solutions of payment collection business simply, not analyzes its benefits and risks of the parties involved deep, perhaps it is because the unreasonable distribution of benefits and risk-sharing,that lead to a variety of problems. Therefore, this paper considers the logistics companies provide both advance payment and payment collection services (ie, advance - payment collection business), quantitative analyze its key indicators of risk management and control - advance payment rate, expect to provide a scientific basis of decision making for the business risk of logistics enterprises in China, and provides new ideas to solve the outstanding contradictions between a lot of money tied up in inventory and difficulties in financing of SMEs.

\section{The Model Analysis of Advance-Payment Collection Business}

\section{Advance - Payment Collection Operations Processes}

(1) Shipper and logistics companies signed a 《commission entrusted with the collection and distribution contracts》, and deliver the goods to logistics companies;

(2) Logistics enterprises advanced by a certain percentage of the purchase price to the shipper according to the value of the goods;

(3) Logistics enterprises deliver the goods to the delivery on time;

(4) Logistics enterprises give the remaining payment to shipper after deducting freight and procedures fees in a certain period(usually for 30 days).

\section{Logistics Enterprises Risk and Benefit Analysis}

a) Benefit analysis

In this business model, in addition to get cargo transport and other traditional logistics services fees, logistics enterprise also obtain a sum of money without interest because of delayed payment. Logistics enterprises through advance payment for the delivery and collection of money for the shipper to enhance the attractiveness of both buying and selling, expand the market share by special services and acquire new business revenue.

b) Risk analysis

Throughout the course of business, logistics enterprises are mainly facing the default risk from the delivery before the goods to the delivery, and after the shipper repurchases the goods unconditionally when the delivery breaks rule, whether the shipper can repay the advances.payment.

\section{Advance-Advance Payment Collection Service Rate Analysis}

\section{Expected Return Model in Both}

a)Basic assumptions

(1) Logistics companies pay advance payment with its own funds;

(2) When the delivery breaks rule, the shipper repurchases the goods unconditionally, and the repurchase value is less than the initial value;
(3) Not consider the risk of default caused by the shipper, such as cargo quality, quantity, etc;

(4) The procedures fees is change with the return time change,that is $k=b-\lambda(t-T)$, $\mathrm{b}$ is the industry average;

(5) Assume that the logistics enterprises are risk-neutral.

b) Parameter setting

c) Expected return model in both

(1) If the probability of default by the delivery is $Q$, Shipper repurchase the goods and its probability of nonpayment is $P$, then their expected return

$$
\begin{aligned}
& E(T)=\left\{\begin{array}{l}
2 V_{0}+k C_{0}-S-w C_{0}, P \\
2 V_{0}+k C_{0}-S, 1-P
\end{array}\right. \\
& E(S)=\left\{\begin{array}{l}
w C_{0}+S_{0}-\left(C_{0}-C\right)-2 V_{0}-k C_{0} . P \\
S_{0}-\left(C_{0}-C\right)-2 V_{0}-k C_{0} .1-P
\end{array}\right.
\end{aligned}
$$

(2) If the probability of paying the full price on time by the delivery is $1-\mathrm{Q}$, then their expected return

$$
\begin{aligned}
& E(T)=V_{0}+k C_{0}-S+\left(C_{0}-S\right) e^{a(t-T)}-w C_{0} \\
& E(S)=S_{0}-V_{0}-k C_{0}
\end{aligned}
$$

Comprehensively,their expected return model is

$$
\begin{aligned}
E(T)= & (1+Q) V_{0}+\left(k C_{0}-S\right) \\
& +(1-Q)\left(C_{0}-S\right) e^{a(t-T)} \\
& -w C_{0}(Q P+1-Q) \\
E(S)= & S_{0}-Q\left(C_{0}-C\right)-(1+Q) V_{0} \\
& -k C_{0}+P Q w C_{0}
\end{aligned}
$$

\begin{tabular}{|c|c|c|c|}
\hline Symbol & Meaning & Symbol & Meaning \\
\hline$w$ & Advance Payment Rate & $t$ & Settlement period \\
\hline$c_{0}$ & The initial value of the goods & $E(S)$ & $\begin{array}{l}\text { Expected return of the } \\
\text { shipper }\end{array}$ \\
\hline$c$ & $\begin{array}{l}\text { The repurchase value of the } \\
\text { goods }\end{array}$ & $E(T)$ & $\begin{array}{l}\text { Expected return of the } \\
\text { Logistics enterprises }\end{array}$ \\
\hline$k$ & The procedures fees rate & $v_{0}$ & One-way freight \\
\hline$s$ & The cost of logistics services & $Q$ & $\begin{array}{l}\text { Probability of default by } \\
\text { delivery }\end{array}$ \\
\hline$a$ & One-year bank deposit rate & $P$ & $\begin{array}{l}\text { Probability of default by } \\
\text { shipper }\end{array}$ \\
\hline$T$ & Delivery date & $S_{0}$ & $\begin{array}{l}\text { Benefits of obtaining the } \\
\text { cash flow advanced for } \\
\text { shipper }\end{array}$ \\
\hline
\end{tabular}

Make $E(T) \geqq 0, \quad E(S) \geqq 0$,we get the range of $\mathrm{w}$

$$
\begin{aligned}
& \frac{(1+Q) V_{0}+\left(k C_{0}-S_{0}\right)+Q\left(C_{0}-C\right)}{P Q C_{0}} \leq w \\
& \leq \frac{(1+Q) V_{0}+\left(k C_{0}-S\right)+(1-Q)\left(C_{0}-S\right) e^{a(t-T)}}{P Q C_{0}+C_{0}(1-Q)}
\end{aligned}
$$

Table 1.

Parameter setting. 
As the value of $w$ is determined by the logistics companies, first, the logistics companies determine the value of $w$ according to their own income maximum and the probability of default by the delivery, then shipper determines whether to accept the service according to the determined $w$ and the pressure of their own funding needs.

\section{Model Analysis}

a) $Q=1$, when the delivery break rule,

$$
\begin{gathered}
E(S)=S_{0}-C_{0}+C-2 V_{0}-k C_{0}+P w C_{0} \\
E(T)=2 V_{0}+\left(k C_{0}-S\right)-w C_{0} P
\end{gathered}
$$

b) $Q=0$,when the delivery pay the full price on time,

$$
\begin{gathered}
E(S)=S_{0}-V_{0}-k C_{0} \\
E(T)=V_{0}+k C_{0}-S+\left(C_{0}-S\right) e^{a(t-T)}-w C_{0}
\end{gathered}
$$

(7) - (5),we can get this

$$
E(T)=\left(C_{0}-S\right) e^{a(t-T)}-V_{0}-w C_{0}(1-P)
$$

Obviously,the formula (8) is always greater than zero, therefore, the logistics companies will be more concerned about the delivery's default probability for their own interests, that is the value of $Q$. As long as the delivery does not default,then they will be able to get higher returns. As the logistics enterprises paid some advance payment, they abandoned the time value of money, so the following inequality holds on,that is

$$
\begin{aligned}
E(T)= & (1+Q) V_{0}+\left(k C_{0}-S\right) \\
& +(1-Q)\left(C_{0}-S\right) e^{a(t-T)} \\
& -w C_{0}(Q P+1-Q)
\end{aligned}
$$

$$
E(T) \geq w C_{0} e^{a T}
$$

We take equal and get the following equality

$$
w=\frac{(1+Q) V_{0}+\left(k C_{0}-S\right)+(1-Q)\left(C_{0}-S\right) e^{a(t-T)}}{P Q C_{0}+C_{0}\left(1-Q+e^{a T}\right)}
$$

According to equation(9), we can find the value of $w$.

\section{Numerical Analysis}

According to the expression of $w$ in equation (9) , we simulate a group of data to analyzes the values and trends of $w$ when $Q$ and $P$ were collected from different values.

We let $c_{0}=100000, v_{0}=1500, s=3000, a=3.5 \%, T=20, t$ $=50$,

Analyzes when $Q=20 \%$ and $\mathrm{P}=10 \% 、 20 \% 、 30 \% 、 40 \%$ 、 $50 \% 、 60 \%$, the values of $w$. By numerical computing, we obtain the following results.

From Figure 1 we can find that the value of $w$ decreases with the increase of $P$, but the decline was not large.

Analyzes when $P=20 \%$ and $Q=10 \% 、 20 \% 、 30 \% 、 40 \%$ 、 $50 \% 、 60 \%$, the values of $w$. By numerical computing, we obtain the following results.

From Figure 2 we can find that the value of $w$ decreases with the increase of $Q$, and the decline was very large. Comparing Figure 2 and Figure 3, we can show that the value of $w$ is more sensitive to $Q$, the logistics companies will be more concerned about the delivery's default probability,which is consistent with the conclusions of Part IV.

\section{Conclusion}

This paper describes the processes of advance - payment collection business, analyzes the benefits and risk of both

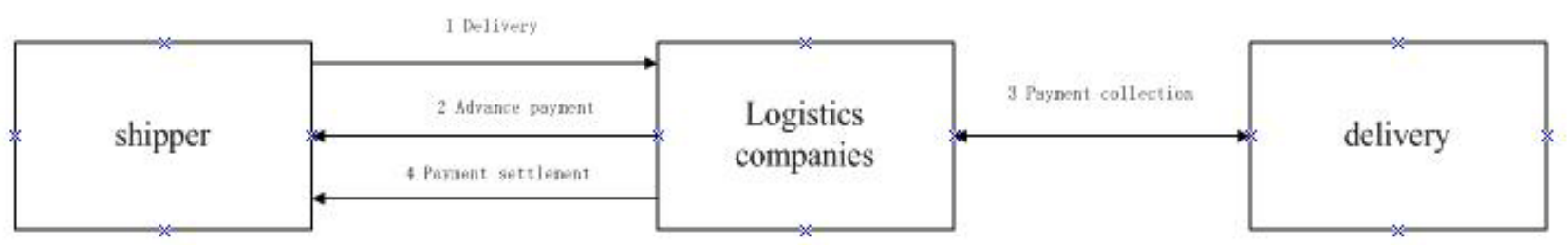

Figure 1.

Advance - payment collection operations processes.

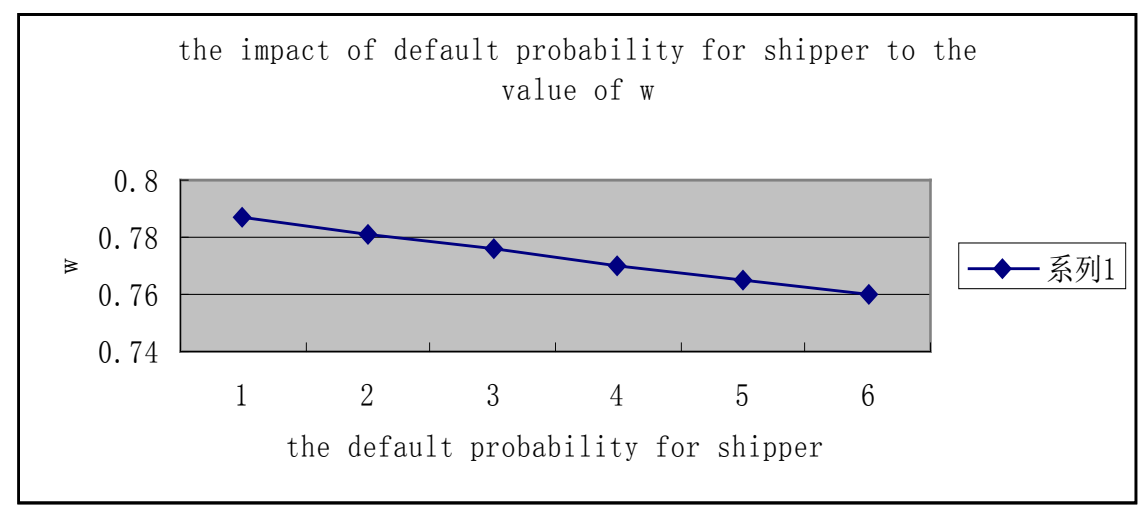

Figure 2.

The impact of default probability for shipper to the value of $w$. 


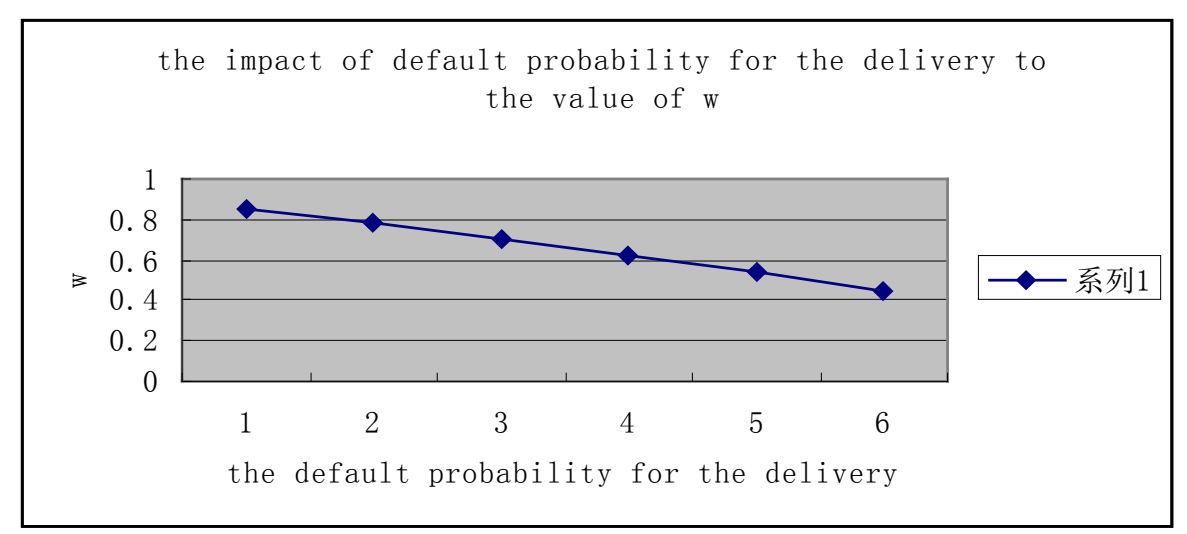

\section{Figure 3.}

The impact of default probability for the delivery to the value of $w$.

Involved, pointed out the major risks facing the logistics enterprises is the default risk from shipper and the delivery, then set a model through the revenue function, solving the key indicators of risk management and control of logistics enterprises - advance payment rate,and through numerical analysis to explore the impact of the default probability from shipper and the delivery on the advance payment rate, the conclusion is that the logistics companies are more concerned about the delivery's default probability. This study can provide a scientific rationale to logistics companies that carry out advance-payment collection business, and show new solutions to shortage of funds for SMEs .

\section{REFERENCES}

Buzacott J A,Zhang R Q. Inventory management with asset-based financing[J]. Management Science. 2004.
Mark Gertzof. The changing face of asset-based lending [J]. Commercial Lending Review,2000.

Wang Gongjiang. The risk and management measures of payment collection carried out by ogistics companies. Commercial Economic Review.2010-06.

Wong Ka Kui, Chen Fulai. The problems and countermeasures of courier payment collection business. Postal Studies,2009-02.

Wang Junfeng. Study on development strategy of payment collection business. Postal Studies.2010-06.

Feng Xia. Study on the payment collection business of third party logistics. Financial Logistics.2007-05.

Xu zhaoxi. Study on financial services contracts of logistics based on the Inventory loans. Zhejiang University School of Management.2008.

Li Yixue,Xu Yu,Feng Gengzhong,Wang Fei.Study on the value ratio of loans of Standard inventory collateral finance business. Operations Research and Management.2006.

Li Yixue.Study on the rate of inventory pledge financing based on the logistics financial. Xi'an Jiaotong University.2007. 